Review Article

\title{
Expression of E-cadherin in prostatic carcinoma: prognostic significance
}

\begin{abstract}
Background and aim: Improvements in the diagnosis of prostate cancer (Pca) have now resulted in screening programs that reveal many more organ confined lesions, with a concomitant increase in the number of radical surgeries. Whether this truly improves overall survival is not clear because of the unpredictable biological potential of these tumors. Not every Pca will progress; on the other hand, metastases still develop in a considerable group of patients with localized disease that are treated radically. The value of grade and clinical stage of the disease is controversial, although the pathological stage seems to be one of the best prognostic factors available to date. Clearly, methods that allow more accurate prediction of the clinical behavior are urgently needed. In this respect, the identification of molecular prognostic markers has now gained considerable attention, So that few of these have yet established clinical value. One of these markers, the epithelial cell adhesion molecule, E-cadherin, is of particular interest since it can function as an invasion suppressor gene. The aim of the current study to assessing the expression of E-cadherin in Pca and determine its relation to different clinicopathological features.
\end{abstract}

Patients and method: Paraffin blocks of 50 Libyan cases of Pca were retrieved. Immunohistochemistry was performed. Membranous staining was evaluated separately. E-cadherin immunoexpression was categorized for statistical analysis. Statistical tests were used to determine the association of E-cadherin with clinicopathological characteristics; age, tumor stage, Gleason score, tumor grade, perineural invasion.

Result: E-cadherin immunostaining results showed membranous E-cadherin expression in Pca. There was no significant correlation between E-cadherin expression and tumor stage and perineural invasion $(\mathrm{P}>0.05)$. How ever, E-cadherin expression was significantly associated with old age (P 0.026), Gleason score (P 0.003), and tumor grade (P 0.004).

Conclusion: The results implicate the usefulness of E-cadherin expression as prognostic tools of Pca.

Keywords: prostate cancer, e-cadherin expression, ihc, prognosis
Volume 4 Issue 3 - 2016

Taghrid Bengallol,' Omran El-Faitori,' Salha Sassi,' Fatma Ben Khaial,' Khaled El Gehani,' Abdelbaset Buhmeida, ${ }^{2}$ Adam Elzagheid' 'Department of Pathology, Benghazi University, Libya, ${ }^{2}$ Center of Excellence in Genomic Medicine Research (CEGMR), King Abdul-Aziz University, Saudi Arabia

Correspondence: Taghrid Bengallol, Department of Pathology, Faculty of Medicine, Benghazi University, Benghazi, Libya, Tel 9258035 I4, Email Sassi.4@buckeyemail.psu.edu

Received: January 17, 2016 | Published: February 22, 2016

\section{Introduction}

Prostate cancer (Pca) is the most common visceral cancer in males, ranking as the second most common cause of cancer related death in men older than 50 years of age after carcinoma of the lung. ${ }^{1}$ In Libya the incidence of prostatic cancer is $7 \%$ of all male malignancies and comes fourth. ${ }^{2}$ It is predominantly disease of older males, with peak incidences between the ages of 65 and 75 years. Latent cancers of prostate are even more common than those that are clinically appeared with an overall frequency of more than $50 \%$ in men older than 80 years of age. ${ }^{1,3}$

This research work proposed to summarize the current knowledge on one of the most important tumor suppressor gene, as E-cadherin. 4,5

E-cadherin is one of the most important molecules in cell-cell adhesion in epithelial tissues. It is localized on the surfaces of epithelial cells in regions of cell-cell contact known as adherens junctions. ${ }^{6}$

As a member of a large family of genes coding for calciumdependent cell adhesion molecules (CAMs), the cadherin glycoproteins are expressed by a variety of tissues, mediating adhesion through homotypic binding. Classical cadherins, $\mathrm{E}$ and $\mathrm{N}$-cadherins being the best characterized play important roles in the formation of tissues during gastrulation, neurulation and organogenesis. ${ }^{7}$
E-cadherin has probably been studied in most detail. It is essential for the formation and maintenance of epithelia, was first identified in chicken, and was originally called L-CAM. ${ }^{8}$ The mouse counterpart of this protein, uvomorulin, ${ }^{9}$ has $80 \%$ identity in both nucleotide and amino acid sequences to the human counterpart. ${ }^{10}$

Besides its role in normal cells, this highly conserved gene can play a major role in malignant cell transformation, and especially in tumor development and progression. The suppression of E-cadherin expression is regarded as one of the main molecular events responsible for dysfunction in cell-cell adhesion. Most tumors have abnormal cellular architecture, and loss of tissue integrity can lead to local invasion. Thus, loss of function of E-cadherin tumor suppressor protein correlates with increased invasiveness and metastasis of tumors, resulting in it being referred to as the "suppressor of invasion" gene. ${ }^{11}$ This study tries to explain the usefulness and accuracy of evaluating Ecadherin expression by using immunohistochemistry as prognostic tools of Pca.

\section{Patients and methods}

\section{Clinicopathological features and follow up data}

The records of all newly diagnosed prostate cancer cases between January 2005 to April 2012 based on availability of representative paraffin blocks were retrieve from the files of the Histopathology 
Department, Benghazi University, 50 libyan male patients were diagnosed with Pca. For each patient, the following information were obtained: age, diagnosis, grading, then the patient files and hospital information system were reviewed to get more information about the type of initial surgical procedure, the PSA level at initial presentation, date of initial diagnosis, staging and type of treatment.

One pathologist confirmed all histological diagnoses and the following histopathological features were recorded included tumour type, tumor stage, Gleason score, tumour grade (well, moderately or poorly differentiated), perineural invasion, metastasis, and status of patients.

\section{E-cadherin Immunostaining}

Fifty samples were available for successful staining by immunohistochemistry. Formalin-fixed, paraffin-embedded prostate tumour tissues were obtained from all 50 samples. Sections were cut serially at $5 \mu \mathrm{m}$ for immunohistochemical (IHC) analysis. IHC analysis was done using the automatic system (BenchMark XT, Ventana Medical Syatem, Inc. Tucson, Arizona, and USA). This fully automated processing of code-labeled slides included baking of the slides, solvent free deparaffinization, antigen retrieval in a cell conditioning buffer CCI (Mild: 36 minutes conditioning, and standard: 60 minutes conditioning), incubation with Rabbit monoclonal antiE-cadherin antibody, $7.0 \mathrm{ml}$ ready-to-use from Spring Bioscience (clone: ECH-6, Catalog no. M3641, 6920 Koll Center Parkway, CA 94566, USA), for $32 \mathrm{~min}$, at 37C. Applicatoin of I-View ${ }^{\mathrm{TM}} \mathrm{DAB}$ Detection Kit (Lot no. B05860AZ), which, includes: I-View DAB HRP, I-View DAB Inhibitor, I-View DAB Biotin, I-view DAB H2O2, and I- view DAB copper. Counterstaining with haematomtoxylin II (C00758) was done for 4 minutes, and post-counterstaining with blueing reagent (B11129) was done for 4 minutes as well. After staining, the sections was dehydrated in ethanol, cleared in xylene, and covered with Mountex and cover slips.

\section{Evaluation of membranous E-cadherin staining}

E-cadherin staining was evaluated using regular light microscope at the magnification of $\mathrm{x} 40$, blinded by the information on tumour grade, stage or clinical outcome. Membranous staining was evaluated. For cell membrane staining, four categories were used, $(+++,++,+$, $0), 0$ ) no expression, no detectable staining in $<10 \%$ of the membrane 1) weak but detectable discontinuous staining present in $10-39 \%$ of the membranes 2 ) moderate, clearly positive discontinuous staining present in $40-90 \%$ of the membranes and 3) intense continuous staining of the membranes create a honeycomb pattern. ${ }^{12,13}$ The membranes index (MI) was calculated with both the intensity of staining and fraction of positively-stained cells taken into account using the following formula:

$$
I=0 * \mathrm{f} 0+1 * \mathrm{f} 1+2 * \mathrm{f} 2+3 * \mathrm{f} 3
$$

Where I; is the staining index, f0-f3 are the fractions of the cells showing a defined level of staining intensity (from 0 to 3 ). Theoretically, the index scores could vary between 0 and 3. ${ }^{14}$

\section{Statistical analysis}

Statistical analyses were performed using the IBM SPSS statistics (IBM Company, NY, and USA) and STATA (StataCrop., Texas, USA) software packages (IBM PASW statistics for windows, version 18.0.3 and STATAA/SE 11.1). Frequency tables were analysed using the Chi-square test, with likelihood ratio (LR) or Fischer's exact test being used to assess the significance of the correlation between the categorical variables. Odds Ratios and their 95\% Confidence
Intervals $(95 \% \mathrm{CI})$ were calculated where appropriate, using the exact method. Difference in the means of continuous variables was analysed using non-parametric tests (Mamm-Whitney or Kruskal-Wallis) and multiple independent samples, respectively. Analysis of variance (ANOVA) was only used deriving the mean values (and their 95\% CI) of each individual stratum.

In all tests, the values $p<0.05$ were regarded statistically significant. Results were represented in tables and figures using Microsoft Office Excel.

\section{Results}

\section{E-cadherin expression pattern in prostatic cancer}

In the 50 primary prostate cancers, heterogeneous staining patterns were observed in malignant glands with alternating patterns of strong, moderated and weak or negative staining in adjacent glands and the expression of this marker was membranous in the primary prostate cancer cells. The staining patterns of E-cadherin in primary prostatic carcinoma are illustrated in Figure 1-4.

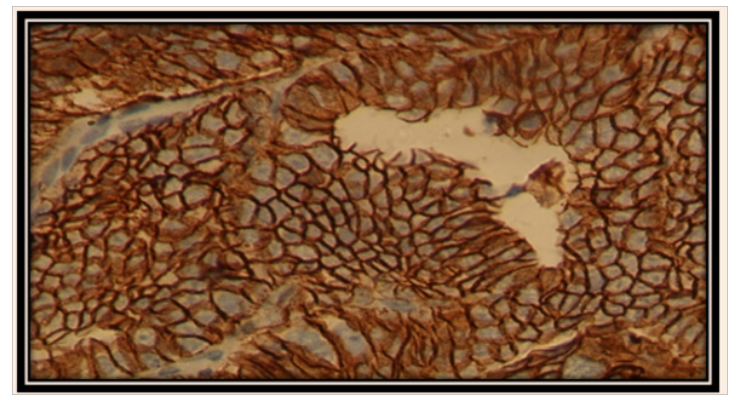

Figure I Strong membranous E-cadherin expression in Pca cell $(\times 40)$. Histopathology, Department. Benghazi University.

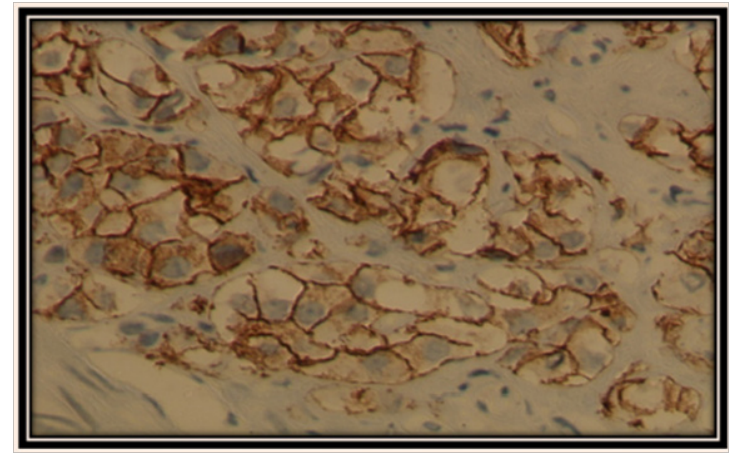

Figure 2 Moderate membranous E-cadherin expression in Pca cell $(\times 40)$. Histopathology, Department,Benghazi University.

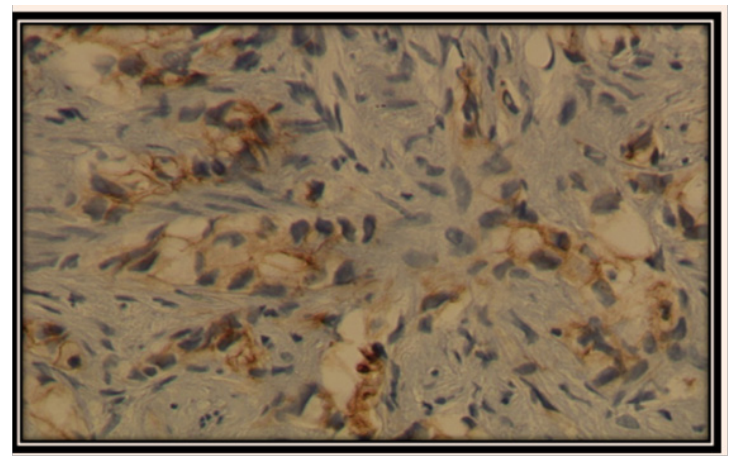

Figure 3 Weak membranous E-cadherin expression in Pca cell $(\times 40)$. Histopathology, Department, Benghazi University. 


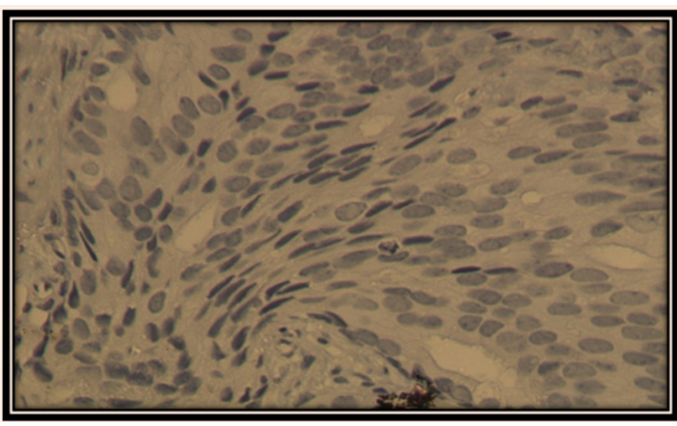

Figure 4 Negative E-cadherin expression in Pca $(\times 40)$. Histopathology, Department, Benghazi University.

\section{Correlation of E-cadherin expression with clinicopathological features}

The distribution of E-cadherin in tumor samples in relation to clinicopathological features is presented in (Table 1) using different cut points (mean, $0,1,2,3,2$ - teir score $(0,1 \mathrm{Vs} 2,3)$ and $(0 \mathrm{Vs} 1,2,3)$.

\section{Discussion}

Cancer of the prostate (Pca) is currently the second most common cause of cancer death in men. In developed countries Pca accounts for $15 \%$ of male cancers compared with $4 \%$ of male cancers in developing countries. ${ }^{15}$

Progressive elucidation of the molecular mechanisms contributing to prostate cancer cell growth, survival, and metastasis may lead to better treatments for established prostate cancer. ${ }^{16}$

Progressive accumulation of somatic mutations in a number of different genes characterizes the process of tumorigenesis. Many genes involved in the process of tumorigenesis are components of one of a great many signal transduction pathways through which signals traffic via molecular networks. It is now apparent that epithelial malignancy can in certain aspects be explained by alterations in the adhesive properties of neoplastic cells. ${ }^{17}$

Malignant carcinoma cells are characterized in general by poo intercellular adhesion, loss of the differentiated epithelial morphology and increased cellular motility. Down regulation or a complete shutdown of E-cadherin expression, mutation of the E-cadherin gene, or other mechanisms that interfere with the integrity of the adherens junctions, are observed in carcinoma cells. In human tumors, the loss of E-cadherin-mediated cell adhesion correlates with the loss of the epithelial morphology and with the acquisition of metastatic potential by the carcinoma cells. ${ }^{18}$ Thus, a tumor invasion/suppressor role has been assigned to this gene. ${ }^{19}$

Immunohistochemical studies have suggested that E-cadherin may be a useful prognostic marker in prostate cancer. ${ }^{20}$ The study tries to evaluate E-cadherin as a potential biomarker of disease progression in patients with clinically organ-confined prostate cancer who undergo radical prostatectomy. ${ }^{2}$

To determine the potential prognostic significance of the findings, prostate cancer specimens from 50 patients were evaluated immunohistochemically using specific antibodies raised against E-cadherin. The results were related to age, Gleason score, histological grade, tumour stage, and perineural invasion.

The current study illustrated some clinicopathological characteristics of Pca patients and revealed that the mean age of the patients was 73 years, about $24(48 \%)$ of them were less than or equal to 73 year and $26(52 \%)$ of them was older than 73 years.

Regarding TNM staging of Pca, it is found that majorty of patients $37(74 \%)$ had tumor at stage IV while others, 13 (26\%) have had tumor at stage II, III.

For Gleason scoring system of the tumor, the study find out that 2 (4\%) of patients had Gleason score 6, 17 (34\%) for G7 which consider moderately differentiated, and 11(22\%) forG8, 13 (26\%) for G9 and $10(7 \%)$ for $\mathrm{G} 10$ which considered as poorly differentiated, that is mean more than two third of patients tumors were poorly differentiated, this in agreement with results reported by De Marzo et al. ${ }^{21}$ Rhodes et al. ${ }^{22}$ Bohmeida et al ${ }^{23}$

This result influences the grades of Pca in the patients where more than $60 \%$ showed poor differentiated tumor $31(62 \%)$ compare to only 19 (38\%) moderately differentiated.

This work elicited that most of Pca patients 39 (78\%) had no perineural invasion while only in $11(22 \%)$ of them, the invasion was present.

Regarding distant metastasis of the Pca, the study revealed that $37(74 \%)$ presented with distant metastasis M1 in comparison to $12(24 \%)$ did not present with metastasis M0.Out of 50 patients, data about metastasis was missed or not available in $1(2 \%)$ of them.

Histopathologically, only $1(2 \%)$ of Pca was found to be of ductal carcinoma type but the vast majority of the tumor was mucinous adenocarcinoma type 49 (98\%).

Lastly, about the status of the patients, $21(42 \%)$ of them were died and $18(36 \%)$ were alive and unfortunately no data were available of $11(22 \%)$.

The staining patterns of E-cadherin in primary prostatic carcinoma of this sample was worked out in Histopathology Department and illustrated in Figures 1-4. Where heterogeneous staining patterns were observed in malignant glands with alternating patterns of strong and weak or negative staining in adjacent glands and the expression of this marker was membranous in the primary prostate cancer cells.

In the present study, the distribution of the expression of membranous E-cadherin in tumor samples in relation to clinicopathological features using different cut points (mean, 0,1,2,3, 2- teir score $(0,1 \mathrm{Vs} 2,3)$ and $(0 \mathrm{Vs} 1,2,3)$ (Table 1).

Mean E-cadherin expression (1.27) was determined for each of the clinically localized prostate cancer cases. Membranous staining was recorded as low (aberrant) or high (normal). Aberrant E-cadherin expression showed a statistical trend toward an association with age of patient at time of diagnosis $(\mathrm{p}=0.026)$, higher Gleason score $(\mathrm{P}=0.003)$, and grade $(\mathrm{P}=0.004)$.

In the current study there is significant statistical correlation between membranous E-cadherin expression and the age of patients were $(\mathrm{P}=0.026)$. However study done by, ${ }^{24}$ who reported that the expression of E-cadherin in colorectal cancer was associated with age at diagnosis

The present study revealed that the expression of membranous E-cadherin was significantly associated with age at diagnosis in that tumors of younger patients $\leq 73$ years than tumors' of the older patients $<73$ years $(\mathrm{P}=0.026)$.

E-cadherin expression were also found to be significantly associated with higher Gleason score $(\mathrm{P}=0.03,0.029$ and 0.003$)$, that is mean the tumors with higher Gleason score express E-cadherin more. 
In addition, E-cadherin expression was also showed significant correlation with higher tumor grades $(\mathrm{p}=0.03,0.05$ and 0.004$)$. According to this results membranous E-cadherin expression was correlated with Gleason score and tumor grade were $(\mathrm{P}=0.003$, $\mathrm{P}=0.004$ ) respectively (Table 1 ) and these results are in agreement with those of ${ }^{25,26}$ as well as other studies which reported that aberrant E-cadherin staining correlated with loss of differentiation (Gleason score) by. $22,27-34$,

However Köksal ${ }^{35}$ reported that aberrant staining of E-cadherin not correlated with Gleason score. ${ }^{35}$ Ray et al. ${ }^{36}$ also demonstrated that E-cadherin staining was not associated with Gleason score.

The discrepancy between this results and other may be attributed to significant differences in the methodologies employed for samples selection, immunostaining techniques, statistical analysis, and the number of studied patients may play a role, also E-cadherin evaluation under the microscopic is subjective and inter observer error may be happen.
Moreover, No statistically significant associations was found between E-cadherin expression in tumors and TNM staging of the tumor and Perineural invasion $(\mathrm{p}=0.349$ and 0.307$)$ respectively (Table 1).

It is observed that no significant statistical association between membranous E-cadherin expression and tumor stage $(p>0.349)$ and this result is in agreement with Jaggi ${ }^{32}$ who reported that E-cadherin membranous expression were not significantly associated with final pathological stage where $\mathrm{P}$ value more than $0.05 .{ }^{32}$ In other hand, the results of this study is not in agreement with the study done by $y^{31,37,38}$ who reported that membranous E-cadherin expression correlated with pathological stage.

It is also reported that, there is no correlation between membranous E-cadherin expression and perineural invasion, $(\mathrm{p}>0.307)$ (Table 1).

Table I Expression of membranous E-cadherin in Libyan Pca patients as related to clinicpathological data

\begin{tabular}{|c|c|c|c|c|c|c|c|c|c|}
\hline \multirow{2}{*}{\multicolumn{2}{|c|}{$\begin{array}{l}\text { Clinicpathological } \\
\text { features }\end{array}$}} & \multicolumn{2}{|c|}{$\begin{array}{l}\text { Mean of E-cadherin } \\
\text { expression }\end{array}$} & \multirow{2}{*}{ P-Value } & \multicolumn{4}{|c|}{ E-Cadherin final index score } & \multirow{2}{*}{ value } \\
\hline & & $<$ mean & >mean & & 0 & 1 & 2 & 3 & \\
\hline \multirow{3}{*}{ Age } & $\leq 73$ & $10(45.5 \%)$ & II (39.3\%) & & $4(30.8 \%)$ & $6(85.7 \%)$ & $4(23.5 \%)$ & $7(53.8 \%)$ & \multirow{3}{*}{0.026} \\
\hline & $>73$ & $12(54.5 \%)$ & $17(60.7 \%)$ & 0.661 & $19(69.2 \%)$ & I (14.3\%) & $13(76.5 \%)$ & $6(46.2 \%)$ & \\
\hline & I & $3(13.6 \%)$ & $\mathrm{I}(3.7 \%)$ & & $2(15.4 \%)$ & $\mathrm{I}(\mathrm{I} 4.3 \%)$ & $0(0 \%)$ & $\mathrm{I}(7.7 \%)$ & \\
\hline \multirow[t]{2}{*}{ Stage } & II & $3(13.6 \%)$ & $5(18.5 \%)$ & \multirow{2}{*}{0.431} & $3(23.1 \%)$ & $0(0 \%)$ & $2(12.5 \%)$ & $3(23.1 \%)$ & \multirow{2}{*}{0.509} \\
\hline & IV & $16(72.2 \%)$ & $2 \mathrm{I}(77.8 \%)$ & & $8(61.5 \%)$ & $6(85.7 \%)$ & 14(87.5\%) & $9(69.2 \%)$ & \\
\hline \multirow[t]{2}{*}{ Gleason score } & $2=$ Intermediate & I I (52.4\%) & $8(28.6 \%)$ & & $9(75 \%)$ & $2(28.6 \%)$ & $4(23.5 \%)$ & $4(30.8 \%)$ & \multirow{3}{*}{0.03} \\
\hline & 3= High & $10(47.6 \%)$ & 20(7I.4\%) & 0.139 & $3(25 \%)$ & $5(71.4 \%)$ & $13(76.5 \%)$ & $9(69.2 \%)$ & \\
\hline \multirow{2}{*}{ Grade } & 2= Moderated & $10(52.6 \%)$ & $9(32.1 \%)$ & & $8(80 \%)$ & $2(28.6 \%)$ & $4(23.5 \%)$ & $5(38.5 \%)$ & \\
\hline & 3= Poor & $9(47.4 \%)$ & $19(67.9 \%)$ & 0.16 & $2(20 \%)$ & $5(7 \mid .4)$ & 13(76.5\%) & $8(61.5 \%)$ & \multirow[t]{2}{*}{0.03} \\
\hline \multirow{2}{*}{$\begin{array}{l}\text { Perineural } \\
\text { invasion }\end{array}$} & $0=\mathbf{N} 0$ & $13(68.4 \%)$ & $22(8 \mid .5 \%)$ & & $8(72.7 \%)$ & $4(66.7 \%)$ & |4(87.5\%) & $9(69.2 \%)$ & \\
\hline & $I=$ Yes & $6(31.6 \%)$ & $5(18.5 \%)$ & 0.307 & $3(27.3 \%)$ & $2(33.3 \%)$ & $2(12.5 \%)$ & $4(30.8 \%)$ & 0.606 \\
\hline
\end{tabular}

Table 2 Expression of membranous E-cadherin in Libyan Pca patients as related to clinic pathological data. Significant and border- line results are in BOLD

\begin{tabular}{|c|c|c|c|c|c|c|c|}
\hline \multirow{2}{*}{$\begin{array}{l}\text { Clinicopathological } \\
\text { features }\end{array}$} & & \multicolumn{2}{|c|}{ E-Cadherin expression score } & \multirow[b]{2}{*}{ p-value } & \multicolumn{2}{|c|}{ E-Cadherin expression Score } & \multirow{3}{*}{ p-value } \\
\hline & & $\begin{array}{l}0,1 \text { vs } 2 \\
0,1\end{array}$ & 2,3 & & $\begin{array}{l}0 \text { vs } 1,2,3 \\
0\end{array}$ & $1,2,3$ & \\
\hline \multirow{3}{*}{ Age } & $\leq 73$ & $10(50 \%)$ & II (36.7\%) & \multirow{3}{*}{0.349} & $4(30.8 \%)$ & $17(45.9 \%)$ & \\
\hline & $>73$ & $10(50 \%)$ & $19(63.3 \%)$ & & $9(69.2 \%)$ & $9(54.1 \%)$ & \multirow[t]{2}{*}{0.34} \\
\hline & I & $3(15 \%)$ & $\mathrm{I}(3.4 \%)$ & & $2(15.4 \%)$ & $2(5.6 \%)$ & \\
\hline \multirow[t]{2}{*}{ Stage } & II & $3(15 \%)$ & $5(17.2 \%)$ & \multirow{2}{*}{0.349} & $3(23.1 \%)$ & $5(\mid 3.9 \%)$ & \multirow{2}{*}{0.353} \\
\hline & IV & I4(70\%) & $23(79.3 \%)$ & & $8(61.5 \%)$ & $29(80.6 \%)$ & \\
\hline \multirow{2}{*}{ Gleason Score } & 2= Intermediate & II(57.9\%) & $8(26.7 \%)$ & & $9(75 \%)$ & $10(27 \%)$ & \multirow{3}{*}{0.003} \\
\hline & $3=\mathrm{High}$ & $8(42.1 \%)$ & $22(73.3 \%)$ & 0.029 & $3(25 \%)$ & $27(73 \%)$ & \\
\hline \multirow{2}{*}{ Grade } & 2= Moderated & $10(58.8)$ & $9(30 \%)$ & & $8(80 \%)$ & II (29.7\%) & \\
\hline & $3=$ Poor & $7(41.2 \%)$ & $21(70 \%)$ & 0.053 & $2(20 \%)$ & $26(70.3 \%)$ & \multirow[t]{2}{*}{0.004} \\
\hline \multirow{2}{*}{ Per Neural Ivasion } & $0=\mathbf{N} 0$ & $12(70 \%)$ & $23(79.3 \%)$ & & $8(72.7 \%)$ & $27(77.1 \%)$ & \\
\hline & $I=$ Yes & $5(29.4 \%)$ & $6(20.6 \%)$ & 0.503 & $3(27.3 \%)$ & $8(22.9 \%)$ & 0.765 \\
\hline
\end{tabular}

\section{Conflicts of Interest}

The authors declare no conflict of interest.

\section{Acknowledgments}

None.

\section{Funding}

None.

\section{References}

1. Alfituri O. Systemic pathology. 1st edn. 2007;1(7):212-215.

2. ElMistiri M, Pirani M, El Sahli N, El Mangoush M, Attia A, et al. Cancer profile in Eastern Libya: incidence and mortality in the year 2004. Ann Oncol. 2010;21(9):1924-1926.

3. Robbins cotran. Basic pathology. 2007;8(18): 698-699.

4. Berx G, Staes K, van Hengel J, et al. Cloning and characterization of the human invasion suppressor gene E-cadherin (CDH1). Genomics. $1995 ; 26(2): 281-289$. 
5. Guilford P. E-cadherin downregulation in cancer: fuel on the fire? Mol Med Today. 1999;5(4):172-177.

6. Gumbiner BM. Cell adhesion: The molecular basis of tissue architecture and morphogenesis. 1996;84(3):345-357.

7. Barth AI, Nathke IS, Nelson WJ. Cadherins, catenins and APC protein: interplay between cytoskeletal complexes and signaling pathways. Curr Opin Cell Biol. 1997;9(5):683-690.

8. Gallin WJ, Sorkin BC, Edelman GM, et al. Sequence analysis of a cDNA clone encoding the liver cell adhesion molecule, L-CAM. Proc Natl Acad Sci USA. 1987;84(9):2808-2812.

9. Ringwald M, Baribault H, Schmidt C, Kemler R The structure of the gene coding for the mouse cell adhesion molecule uvomorulin Nucleic Acids Res. 1991;19(23):6533-6539.

10. Mansouri A, Spurr N, Goodfellow PN, et al. Molecular cloning and chromosomal localization of the gene encoding the human cell adhesion molecule ovomorulin. Differentation. 1998;38:67-71.

11. Vleminckx K, Vakaet L, Mareel M, et al. Genetic manipulation of E-cadherin expression by epithelial tumor cells reveals an invasion supressor role. Cell. 1991;66(1):107-119.

12. Elzagheid A, Kuopio T, Ilmen M, et al. Prognostication of invasive ductal breast cancer by quantification of E-cadherin immunostaining: the methodology and clinical relevance. Histopathology. 2002;41(2):127133.

13. Elzagheid A, Algar A, Bendardaf R, et al. E-cadherin expression pattern in primary colorectal carcinoma and there metastasese reflects disease out come. World J Gasstroenterol. 2006;12(27):4304-4309.

14. Buhmeida A, Elzagheid A, Algar A, et al. Expression of the cell-cell adhesion molecules beta-catenin in colorectal carcinomas and there metastases. APMIS. 2008;116(1):1-9.

15. Heidenreich A, Bellmunt J, Bolla M, et al. EAU guidelines on prostate cancer. Part 1: screening, diagnosis, and treatment of clinically localised disease. Eur Urol. 2011;59(1):61-71.

16. De Marzo AM, DeWeese TL, Platz EA, et al. Pathological and Molecular Mechanisms of Prostate Carcinogenesis: Implications for Diagnosis, Detection, Prevention, and Treatment. J Cell Biochem. 2004;91(3):459477.

17. Pećina-Slaus N. Tumor suppressor gene E-cadherin and its role in normal and malignant cells. Cancer Cell Int. 2003;3(1):17.

18. Rietmacher D, Brinkmann V, Birchmeier C. A Targeted mutation in the mouse E-cadherin gene results in defective preimplantation development. Proc Natl Acad Sci USA. 1995;92(3): 855-859.

19. Efstathiou JA, Liu D, Wheeler JM, et al. Mutated epithelial cadherin is associated with increased tumorigenicity and los of adhesion and of responsiveness to the motogenic tre foil factor 2 in colon carcinoma cells. Proc Natl Acad Sci U S A. 1999;96(5):2316-2321.

20. Cheng L, Nagabhushan M, Pretlow TP, et al. Expression of ECadherin in Primary and Metastatic Prostate Cancer. Am J Pathol. 1996;148(5):1375-1380.

21. Buhmeida A, S Pyrhönen, M Laato, et al. Prognostic factors in prostate cancer. Diagn Pathol. 2006;1: 4.

22. De Marzo AM, Knudsen B, Chan-Tack K, et al. E-cadherin expression as a marker of tumour aggressiveness in routinely processed radical prostatectomy specimens. Urology. 1999;53(4):707-713.

23. Rhodes DR, Sanda MG, Otte AP, et al. Multiplex biomarker approach for determining risk of prostate-specific antigen-defined recurrence of prostate cancer. J Natl Cancer Inst. 2003;95(9):661-668.

24. Elzagheid A, Buhmeda A, Laato M, et al. loss of E-cadherin expression predicts disease recurrence and shorter survival in colorectal carcinoma. APMIS. 2012;120(7):539-548.

25. Ozekinci S, Uzunlar AK, Senturk S, et al. Expression of e-cadherin, COX-2, P53 and BCL-2 in prostate carcinomas: correlation with tumor differentiation and metastatic potential. 2010;24(4):2112-2116.

26. Nagao K, Yamamoto Y, Hara T, et al. Ki67 and BUBR1 May Discriminate Clinically Insignificant Prostate Cancer in the PSA Range $<4 \mathrm{ng} / \mathrm{ml}$. Jpn J Clin Oncol. 2011;41(4): 555-564.

27. Umas R, Schalken JA, Aalder TW, et al. Expression of the cellular adhesion molecules E-cadherin is reduced or absent in high-grage prostate cancer. Cancer Res. 1992;52:5104-5109.

28. Umbas R, Isaacs WB, Bringuier PP, et al. Decreased E-cadherin expression is associated with poor prognosis in patients with prostate cancer. Cancer Res. 1994;54(14):3929-3933.

29. Richmond PJ, Karayiannakis AJ, Nagafuchi A, et al. Aberrant Ecadherin and alpha-catenin expression in prostate cancer: correlation with patient survival. Department of Surgery, Royal Free Hospital, London, United Kingdom. Res. 1997;57(15):3189-3193.

30. Rubin MA, Mucci NR, Figurski J, et al. E-cadherin expression in prostate cancer: a broad survey using high-density tissue microarray technology. Hum Pathol. 2001;32(7):690-697.

31. Kallakury BV, Sheehan CE, Winn-Deen E, et al. Decreased expression of catenins ( $\alpha$ and $\beta)$, p120 CTN, and E-cadherin cell adhesion proteins and $\mathrm{E}$-cadherin gene promoter methylation in prostatic adenocarcinomas Cancer. 2001;92(11):2786-2795.

32. Jaggi M, Johansson SL, Baker JJ, et al. Aberrant expression of Ecadherin and beta-catenin in human prostate cancer. Urol oncol. 2005;23(6):402-406.

33. Algaba F, Arce Y, Fernández S, et al. Adhesion molecules expression as a potential marker of prostate cancer aggressivity. A TMA study of radical prostatectomy specimens. Arch Ital Urol Androl. 2006;78(4):130-134.

34. Musial J, Sporny S, Nowicki A. Prognostic significance of E-cadherin and ezrin immunohistochemical expression in prostate cancer. Pol pathol. 2007;58(4):235-243.

35. Köksal IT, Ozcan F, Kiliçaslan I, et al. Expression of E-cadherin in prostate cancer in formalin-fixed, paraffin-embedded tissues correlation with pathological features. Pathology. 2002;34(3):233-238.

36. Ray ME, Mehra R, Sandler HM, et al. E-cadherin protein expression predicts prostate cancer salvage radiotherapy outcomes. J Urol. 2006;176(4 Pt 1):1409-1414.

37. Kallakury BV, Sheehan CE, Winn-Deen E, et al. Decreased expression of catenins ( $\alpha$ and $\beta$ ), p120 CTN, and E-cadherin cell adhesion proteins and E-cadherin gene promoter methylation in prostatic adenocarcinomas. Cancer. 2001;92 (11):2786-2795.

38. Robbins, Cotran. Pathologic basis of disease. 2004;7 (21):1053 